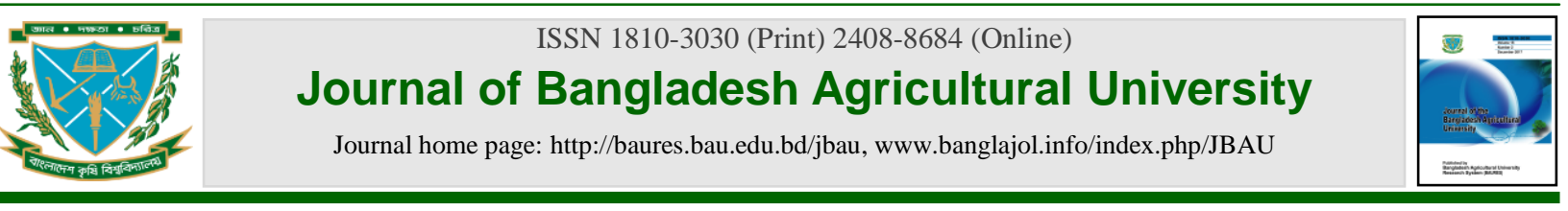

\title{
Reuse of spent mushroom substrate as casing material for the production of milky white mushroom
}

\author{
R. Ashrafi ${ }^{1}$, M. H. Mian ${ }^{2}$, M. M. Rahman ${ }^{2}$ and M. Jahiruddin ${ }^{2}$ \\ ${ }^{1}$ BINA Substation, Jamalpur, Bangladesh Institute of Nuclear Agriculture, Mymensingh-2202, Bangladesh \\ ${ }^{2}$ Department of Soil Science, Bangladesh Agricultural University, Mymensingh-2202, Bangladesh
}

\begin{tabular}{|c|c|}
\hline ARTICLE INFO & Abstract \\
\hline $\begin{array}{l}\text { Article history: } \\
\text { Received: } 10 \text { October } 2017 \\
\text { Accepted: } 12 \text { December } 2017\end{array}$ & \multirow{3}{*}{$\begin{array}{l}\text { An experiment was conducted to reuse waste generated from mushroom farm called composted spent } \\
\text { mushroom substrate (SMS) as casing material for the production of milky white mushroom. The } \\
\text { production trial of milky white mushroom was conducted with five casing mixture viz. Loam soil + Sand } \\
\text { (3:1) (farmer's practice), SMS compost + Sand }(3: 1) \text {, Loam soil }+ \text { SMS compost }+ \text { Sand }(2: 1: 1) \text {, Loam } \\
\text { soil + SMS compost + FYM }(1: 1: 1) \text { and SMS compost + FYM }(1: 1) \text {. Results revealed the suitability of } \\
\text { SMS to reuse as casing materials through composting. Casing treatments containing SMC alone or } \\
\text { combination with sand }(3: 1) \text { and soil + FYM }(1: 1: 1) \text { produced statistically similar yield which were } \\
\text { statistically higher than farmer's practice. Among these three treatments, pH, EC, particle density and } \\
\text { organic carbon ranged between 7.16-7.82, 1.69-1.84 mmhos } \mathrm{cm}^{-1}, 1.52-1.90 \mathrm{~g} \mathrm{cc}-1 \text { and } 11.3 \%-15.8 \% \text {, } \\
\text { respectively. Below or above this range reduced the yield of milky white mushroom. SMC, SMC + Sand } \\
\text { (3:1) and Soil + SMC + FYM }(1: 1: 1) \text { produced statistically similar yield but SMC and SMC + Sand }(3: 1) \\
\text { took shorter time to harvest than Soil + SMC + FYM }(1: 1: 1) \text {. So, SMC or SMC + Sand }(3: 1) \text { can be } \\
\text { recommended to use as casing material. }\end{array}$} \\
\hline $\begin{array}{l}\text { Keywords: } \\
\text { Spent mushroom substrate, } \\
\text { casing material, milky white } \\
\text { mushroom }\end{array}$ & \\
\hline $\begin{array}{l}\text { R. Ashrafi } \\
\text { (reema_ashrafi@yahoo.com) }\end{array}$ & \\
\hline
\end{tabular}

\section{Introduction}

Disposal of spent mushroom substrate is an ever growing concern in the world. Problems arising from solid waste are increasing drastically. Waste management is now a major and growing concern in Bangladesh. The huge amount of mushroom waste is added to the burden of the municipal refuses, especially around the mushroom cultivation complexes. About five kilograms of fresh compost are needed to produce one kilogram of mushrooms (Sample et al., 2001). There was an estimate that about 70,000,000 metric tons of mushroom waste was generated during the year 2007 in the world (Tajbakhsh et al., 2008). Across the country (Bangladesh) per day 15-20 MT of fresh mushrooms and about 60,000-70,000 of spawn packets were produced in the year 2008 (Amin, 2008). Per spawn packet contains $500 \mathrm{gm}$ substrate then $30,000-35,000 \mathrm{~kg}$ spawn were produced per day in 2008. From which it can be calculated that per day about 15-18 MT mushroom wastes were produced in Bangladesh in the year 2008 because an average 0.5 ton mushroom waste is produced from each ton of spawned compost (Levanon et al., 1994).

Calocybe indica, commonly known as milky white mushroom is a tropical mushroom, grows during the summer and well known for its nutritive value. Its robust size, sustainable yield, attractive colour, delicacy, long shelf-life and lucrative market value have attracted the attention of both mushroom consumers and prospective growers (Chakraborty and Sikdar, 2010). Bangladesh has good environmental conditions for the commercial cultivation of milky white mushroom. This mushroom requires a temperature of $30 \sim 35^{\circ} \mathrm{C}$ and a relative humidity of 70 80\% for cultivation, which is conducive to the environment conditions of Bangladesh (Krishnamoorthy et al., 2000). Casing is an important cultural practice of milky mushroom cultivation. Casing means covering the cultivation substrate with a layer of soil or soil like material after spawn run which enhances the transformation of vegetative stage to reproductive stage (Pani, 2012; Suess and Curtis, 2009). Casing the surface of composted substrate fully colonized by mycelium of mushroom is an essential function in stimulation and promoting the development of fruit bodies (Farsi et al., 2011). Recent studies on the constraints in the cultivation of milky mushroom indicated casing is the most important factor affecting the yield. The composition of casing mixture determine its quality (texture, structure, $\mathrm{pH}$, water holding capacity, C:N ratio etc.), which directly affect the mycelial growth in casing layer and initiation of fruiting bodies (Tewari, 2005).

Although different materials may adequately function as a casing layer, peat is commonly used and recommended as a good casing in mushroom cultivation (Gulser and Peksen, 2003). Peat is not so available in many mushroom growing areas. It is a costly and nonrenewable input. Not only the import cost of peat but also the depletion of its available resources worldwide discourages the investors to use peat as casing layer (Sassine et al., 2007). After that many materials, alone or in combination, have been used as casing both 
commercially and experimentally (Gimenez and Gonzalez, 2008). It was stated that farmyard manure and loamy soil in 1:1 ratio in the production of Agaricus bisporus (Hayes and Shandilya, 1977) and the mixture of soil and sand 1:1 ratio in the production of Calocybe indica (Purkayastha and Chandra, 1985) had supported better fructification compared to other substrates. Sharma et al. (1997) evaluated 16 combinations of casing material and reported that 2 years old cowdung patties were excellent casing material, using 1 inch thick in milky mushroom cultivation. Gupta and Dhar (1993) reported that the addition of $0.10 \%$ grain spawn (on the basis of casing soil) and 1.25 to $1.75 \mathrm{~kg} / \mathrm{m}^{2}$ compost spawn at casing improved the sporophore yield of button mushroom. In Indian subcontinent, use of farm yard manure (FYM) as a casing medium for mushroom cultivation has been in vogue because of its easy availability and non availability of peat moss generally used for casing in Europe and USA (Choudhary, 2011).

In Bangladesh, moss/peat is not available. Farmers use the mixture of soil and sand as casing material. It is recognized that spent mushroom waste contains rich and valuable organic materials and is convenient for recycling in different forms (Danny, 1992; Szmidt and Convay, 1995). So, there is a great opportunity to use SMS as casing material in milky white mushroom production. But to reduce $\mathrm{EC}$ and remove predecomposed vegetative matter, SMS must be recomposted and leaching for a length of time which makes it a suitable component of the casing layer for mushroom production. Composting is the natural breakdown process of organic residues. Composting transforms raw organic waste materials into biologically stable, humic substances.

The environmental degradation caused by inadequate disposal of spent mushroom waste can be expressed by the contamination of surface and ground water through leachate, soil contamination through direct waste contact or leachate, air pollution by burning of wastes, spreading of diseases by different vectors like birds, insects and rodents, or uncontrolled release of methane by anaerobic decomposition of waste (Visvanathan and Glawe, 2010). Methods of satisfactory waste disposal have not been in Bangladesh (BCAS, 2012). For the management of mushroom waste there is needed to devise proper ways and means for utilization of spent mushroom substrates instead of disposing them as undesirable waste. Reuse of SMS for the production of milky white mushroom may be a good solution of mushroom waste disposal. Therefore the objectives of the present study, to achieve the cherished goal, were planned to use spent mushroom substrate through composting and determine the effectiveness of using spent mushroom compost as casing material for milky white mushroom (Calocybeindica) production.

\section{Materials and Methods}

The experimental trial was conducted at the laboratory of the Department of Soil Science of Bangladesh Agricultural University, Mymensingh with the cooperation of Horticulture Centre, Kewatkhali, Mymensingh during the period of June-October of 2010 and 2011.

\section{Composting of spent mushroom substrate to use as casing media}

Preparation and production of spent mushroom compost: Spent mushroom substrate (SMS) was collected from mushroom farm and existing clods were broken by a hammer. The feedstock of shredded spent mushroom substrate was heaped into piles under a cover shed over a 14-week period. Pile was constructed at a size of $5 \mathrm{ft} \times 2 \mathrm{ft} \times 2.33 \mathrm{ft}$ (length $\times$ width $\times$ height). Compost materials were spreaded in the pile by maintaining a layer of 6-inch SMS with 2-inch layer containing cowdung and grasses for rapid composting. The composting materials were turned at 15-day intervals up to 10 weeks of composting. Following active composting method, the composted material was allowed for curing over a minimum of one month to create more stable compost and to reduce the potential for plant phytotoxicity. Temperature of the pile was monitored after every 2 days during the process using thermometer inserted near the centre of the pile at three different points.

Compost maturity tests: Compost maturity and stability were tested by following the tests of Jar or bag, germination and phytotoxicity. Jar or bag test was performed by taking moistened SMS compost in a sealed plastic pot and kept in room temperature for about a week. Bad smell indicated incomplete composting. So, the composting was continued up to obtaining the earthy smell. Then germination percentage test was performed with raddish seeds. When the germination percentage of SMC was found less than the plain soil, more time was allowed for composting. Finally phytotoxicity test was done by allowing the seedlings to grow for 10 days and then uprooted carefully to observe whether any toxic symptoms were shown on the shoots and roots of the seedlings.

\section{Production trial of milky white mushroom with experimental casing materials}

Species: Calocybe indica commonly known as milky white mushroom was used in this experiment. The suitable temperature for this mushroom is $30-35^{\circ} \mathrm{C}$ and relative humidity is $70-80 \%$.

Treatments: Five treatments were used in this experiment, as follows:

$\mathrm{T}_{1}$ : Control [Soil + Sand (3:1)]

$\mathrm{T}_{2}$ : $\mathrm{SMC}$ 
$\mathrm{T}_{3}: \mathrm{SMC}+$ Sand $(3: 1)$

$\mathrm{T}_{4}:$ Soil + SMC + FYM (1:1:1)

$\mathrm{T}_{5}: \mathrm{SMC}+\mathrm{FYM}(1: 1)$

Preparation of casing material: Prepared spent mushroom compost (SMC) was used as casing material. Loam soil, sand and FYM were mixed with SMC at different proportions as per treatments. Casing materials were analyzed by following standard methods to determine particle density, pH (Jackson, 1973), EC and OC (dry combustion method) contents.

Spawn preparation: Straw (T. Aman rice) based substrate was used to cultivate milky white mushroom. The straw was first chopped into 5-8 cm length and then kept in water in a big pot to wet for 12 hours. After that excess moisture was removed from the straw to maintain moisture at approximately $70 \%$. The wet straw was then mixed with sawdust at half of the straw weight and wheat bran at half of the sawdust weight. $\mathrm{CaCO}_{3}$ was also mixed at the rate of $1 \%$ mixture. One $\mathrm{kg}$ of mixture substrate was poured into polypropylene bag and the opening of the bag was plugged with cotton and secured with plastic neck. The bags were autoclaved at $121^{\circ} \mathrm{C}$ with 15 psi for 1 hour and incubated with 2-teaspoonful of a mother culture after cooling the packet. The spawn packets were kept in a dark room for incubation at 24$28^{\circ} \mathrm{C}$ for about 1 month up to the completion of mycelial growth.
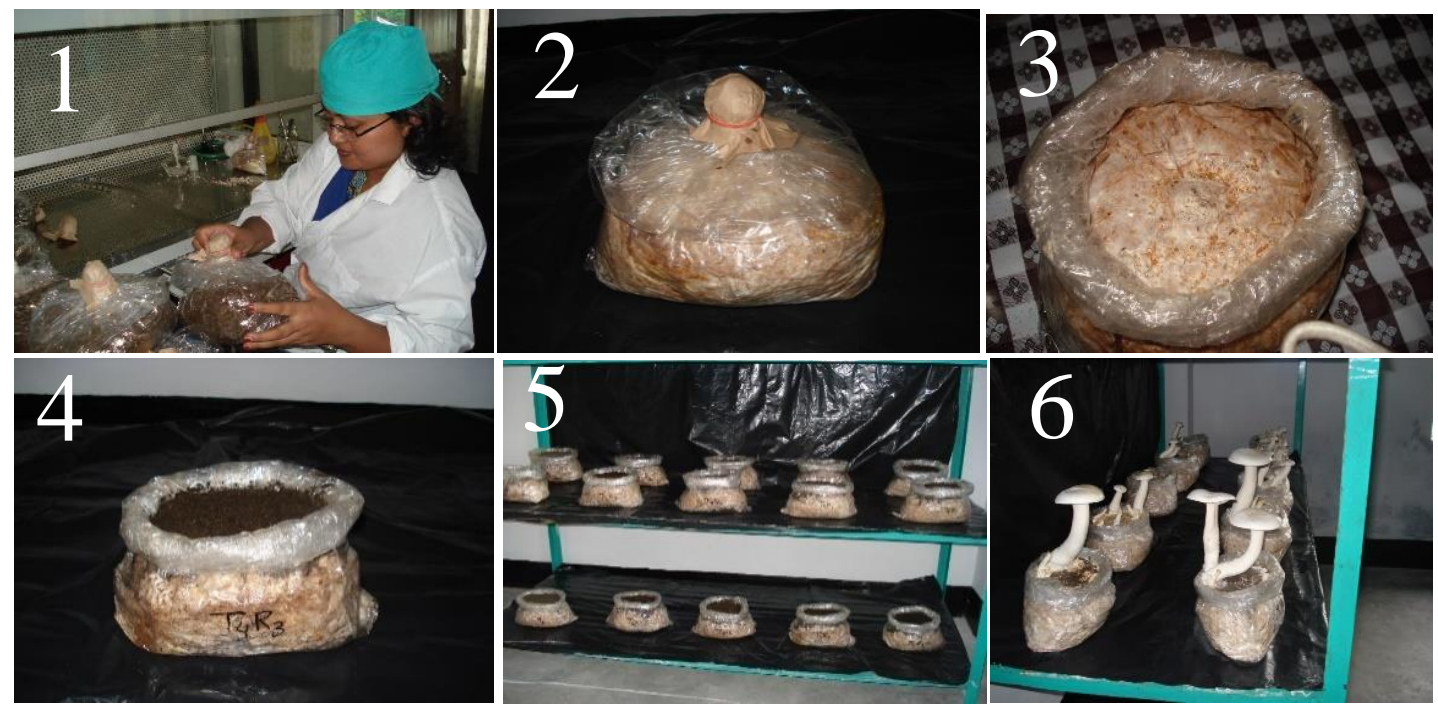

Fig 1. Different steps of milky white mushroom production ((1) Spawn packet preparation, (2) After completion of mycelial colonization, (3) Preparation for casing, (4) Casing (5) Pinhead formation and (6) Fruiting body formation

Statistical analysis: The data were analyzed according to standard methods using theMStat-C computer programme. Means were computed following Duncan's Multiple Range Tests at 5\% level (Gomez and Gomez, 1984).

\section{Results}

\section{Changes in temperature during SMS composting process}

In the composting pile, temperature was increased quickly from $32^{\circ} \mathrm{C}$ to $50^{\circ} \mathrm{C}$ within 3 days and remained the same for 5 weeks (Fig. 1). Temperature reached a maximum of $61^{\circ} \mathrm{C}$ and thereafter temperature was stabilized at $33^{\circ} \mathrm{C}$ which were close to air temperature. 


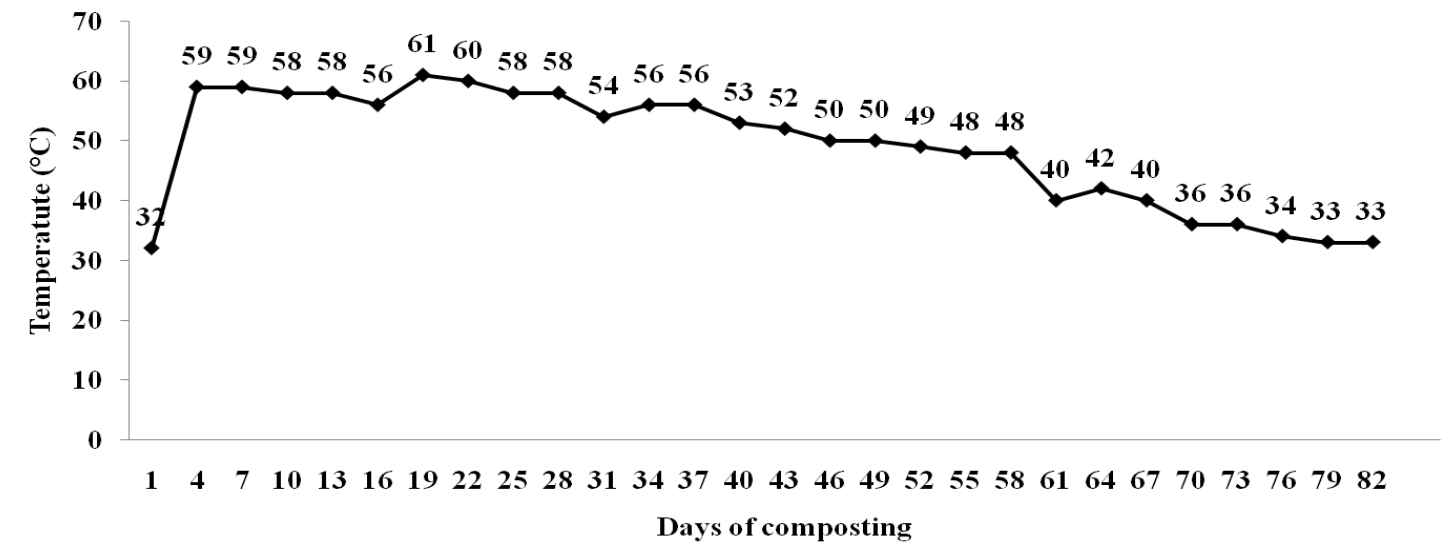

Fig. 2. Changes in temperature of SMS during composting process

\begin{abstract}
Maturity of the composted spent mushroom substrate

After composting of SMS, a pleasant soil-like smell was observed in the bag test. Again 100\% seed germination was observed in compost and in the mixture of compost with soil at 1:1 ratio medium, whereas $90 \%$ seed germination was observed in soil medium. After 10 days of germination, normal growth of root and seedlings were observed.
\end{abstract}

Use of SMS compost as casing media for the production of milky white mushroom

Composted spent mushroom substrate was studied to use as a casing material alone or in combination with loamy soil, sand and FYM through evaluation of the yield and other characters of milky white mushroom. Control
Treatment $\mathrm{T}_{1}$ [Soil + Sand (3:1)] was also considered as farmer's practice.

Time required for casing to primordia initiation, primordia initiation to $1^{\text {st }}$ and $3^{\text {rd }}$ harvest: Time required for casing to primordia initiation and primordia initiation to $3^{\text {rd }}$ harvest was varied significantly due to different casing treatments (Table 1). But there was not observed significant differences in the time required for primordia initiation to $1^{\text {st }}$ harvest. Time for primordia initiation varied between 9.17 and 12.17 days where 9.17 days was observed in treatment $T_{3}$ with statistical similar result of treatment $\mathrm{T}_{1}(9.50$ days $)$ and $\mathrm{T}_{2}(9.83$ days) and 12.17 days in treatment $\mathrm{T}_{4}$ with statistically identical result of $\mathrm{T}_{5}$ (12.0 days). Time required for the $3^{\text {rd }}$ harvest showing a variation from 48 days to 72 days where 48 days were for treatment $T_{5}$ and 72.0 days for treatment $\mathrm{T}_{1}$.

Table 1. Effects of spent mushroom compost on the time for casing to primordia initiation, primordia initiation to the $\mathbf{1}^{\text {st }}$ harvest and $3^{\text {rd }}$ harvest of milky white mushroom

\begin{tabular}{lccc}
\hline Treatments & $\begin{array}{c}\text { Casing to primordia } \\
\text { initiation } \\
\text { (day) }\end{array}$ & $\begin{array}{c}\text { Primordia initiation } \\
\text { to 1st harvest } \\
\text { (day) }\end{array}$ & $\begin{array}{c}\text { Primordia initiation to } \\
\text { 3rd harvest } \\
\text { (day) }\end{array}$ \\
\hline $\mathrm{T}_{1}$ : Control [Soil + Sand $\left.(3: 1)\right]$ & $9.50 \mathrm{~b}$ & 8.83 & $72.0 \mathrm{a}$ \\
$\mathrm{T}_{2}$ : SMC & $9.83 \mathrm{~b}$ & 8.50 & $54.0 \mathrm{bc}$ \\
$\mathrm{T}_{3}$ : SMC + Sand (3:1) & $9.17 \mathrm{~b}$ & 8.50 & $52.3 \mathrm{bc}$ \\
$\mathrm{T}_{4}$ : Soil + SMC + FYM (1:1:1) & $12.17 \mathrm{a}$ & 9.17 & $59.3 \mathrm{~b}$ \\
$\mathrm{~T}_{5}:$ SMC + FYM $(1: 1)$ & $12.00 \mathrm{a}$ & 9.33 & $48.0 \mathrm{c}$ \\
level of significance & $* *$ & $\mathrm{NS}$ & $* *$ \\
$\mathrm{SE}( \pm)$ & 0.43 & 0.59 & 2.18 \\
\hline
\end{tabular}

The same letters within a column are not significantly different by Duncan'sMultiple Range Tests at the $5 \%$ level. *= Significant at $5 \%$ level, $* *=$ Significant at $1 \%$ level.

Number of effective fruiting bodies: Significant variation was observed among the treatments in case of number of effective fruiting bodies of mushroom (Table 2). The highest number of effective fruiting bodies was found in treatments $\mathrm{T}_{3}(4.17)$ with statistically identical to $\mathrm{T}_{4}$ treatment (3.83). The lowest number of effective fruiting bodies was noticed in treatment $\mathrm{T}_{1}(2.50)$ which were statistically identical to $T_{2}(2.50)$. 

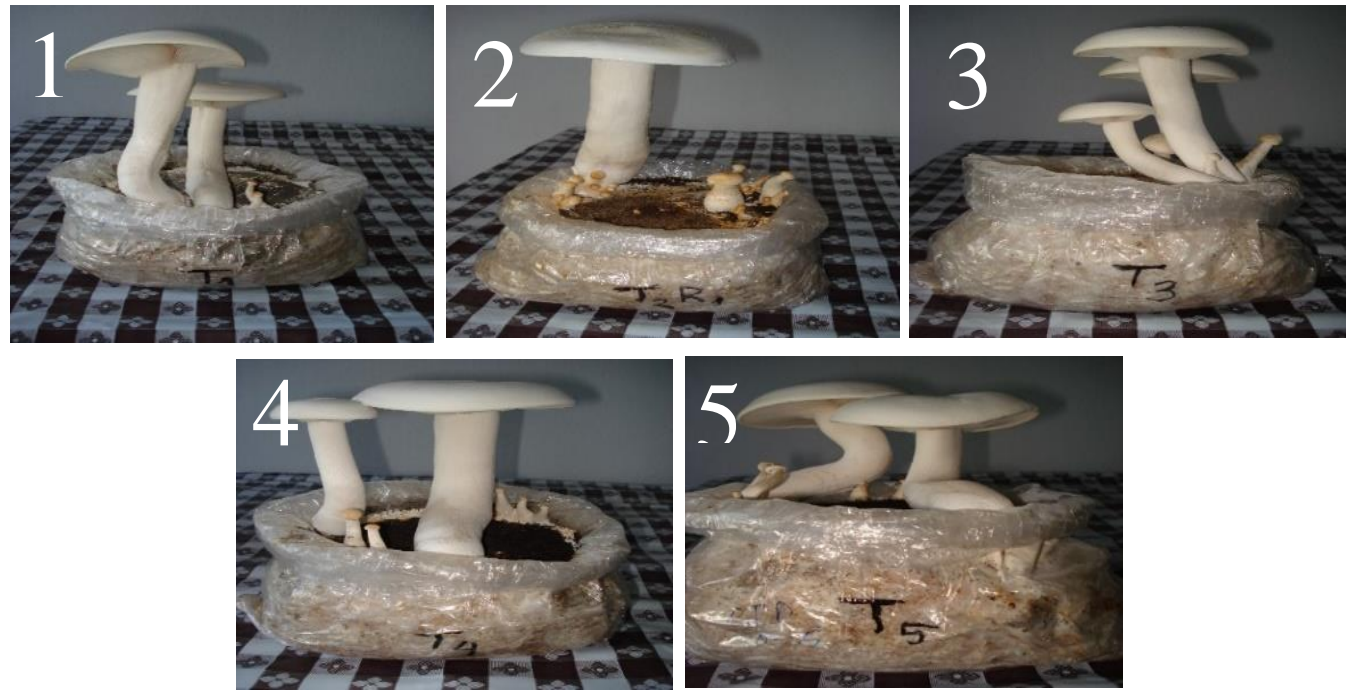

Fig. 3. Fruiting bodies at different treatment during $1^{\text {st }}$ harvest, $\mathrm{T}_{1}$ : Control (Loam soil + Sand, 3:1) (farmer's practice), $\mathrm{T}_{2}: \mathrm{SMS}$ compost + Sand (3:1), $\mathrm{T}_{3}$ : Loam soil + SMS compost + Sand (2:1:1), $\mathrm{T}_{4}$ : Loam soil + SMS compost + FYM (1:1:1) and $\mathrm{T}_{5}$ : SMS compost + FYM $(1: 1)$.

Biological and economic yield of milky white mushroom: Biological and economic yield of milky white mushroom was markedly influenced by casing mixture of SMC with sand, soil and FYM (Table 2). The maximum yield was obtained from treatment $T_{4}$ (biological yield $329 \mathrm{~g} \mathrm{packet}^{-1}$ and economic yield $316 \mathrm{~g} \mathrm{packet}^{-1}$ ) which was statistically similar to treatments $\mathrm{T}_{2}$ (biological yield $312 \mathrm{~g}$ packet $^{-1}$ and economic yield $299 \mathrm{~g} \mathrm{packet}^{-1}$ ) and $\mathrm{T}_{3}$ (biological yield $318 \mathrm{~g} \mathrm{packet}^{-1}$ and economic yield $304 \mathrm{~g} \mathrm{packet}^{-1}$ ). The lowest biological yield was recorded in treatment $T_{1}$ representing farmers' practice (biological yield $258 \mathrm{~g}$ packet $^{-1}$ and economic yield 248 g packet $^{-1}$ ).

Average weight of fruiting bodies: Average weight of fruiting bodies differed with different treatments; however the difference was not statistically significant (Table 2). The highest average weight of fruiting bodies was found in treatment $\mathrm{T}_{2}(126 \mathrm{~g})$ and the lowest in treatment $\mathrm{T}_{3}(76 \mathrm{~g})$.

Table 2. Effects of spent mushroom compost on the number and yield of milky white mushroom

\begin{tabular}{|c|c|c|c|c|}
\hline Treatments & $\begin{array}{c}\text { Effective fruiting } \\
\text { bodies } \\
\text { (no. packet }^{-1} \text { ) }\end{array}$ & $\begin{array}{c}\text { Biological } \\
\text { yield } \\
\left.\text { (g packet }^{-1}\right)\end{array}$ & $\begin{array}{c}\text { Economic } \\
\text { yield } \\
\left(\text { (g packet }^{-1}\right)\end{array}$ & $\begin{array}{c}\text { Weight of } \\
\text { fruiting } \\
\text { bodies (g) }\end{array}$ \\
\hline Control [Soil + Sand (3:1)] & $2.50 \mathrm{c}$ & $258 \mathrm{~b}$ & $248 \mathrm{~b}$ & 103 \\
\hline $\mathrm{T}_{2}: \mathrm{SMC}$ & $2.50 \mathrm{c}$ & $312 \mathrm{a}$ & $299 \mathrm{a}$ & 126 \\
\hline $\mathrm{T}_{3}: \mathrm{SMC}+$ Sand $(3: 1)$ & $4.17 \mathrm{a}$ & $318 \mathrm{a}$ & $304 \mathrm{a}$ & 76 \\
\hline $\mathrm{T}_{4}:$ Soil + SMC + FYM $(1: 1: 1)$ & $3.83 \mathrm{ab}$ & 329 a & 316 a & 86 \\
\hline $\mathrm{T}_{5}: \mathrm{SMC}+\mathrm{FYM}(1: 1)$ & $3.17 \mathrm{bc}$ & $262 \mathrm{~b}$ & $251 \mathrm{~b}$ & 83 \\
\hline Level of significance & $*$ & $* *$ & $* *$ & NS \\
\hline $\mathrm{SE}(\underline{ \pm})$ & 0.29 & 8.22 & 5.08 & 11.12 \\
\hline
\end{tabular}

The same letters within a column are not significantly different by Duncan's Multiple Range Tests at the $5 \%$ level. *= Significant at $5 \%$ level, $* *=$ Significant at $1 \%$ level.

Length of stalk, diameter of stalk, diameter of pileus and thickness of pileus: The effect of casing material of SMC on the length of stalk, diameter of stalk, diameter of pileus and thickness of pileus were significant due to different casing mixtures of SMC with sand, soil \&
FYM (Table 3). The longest stalk was recorded with treatment $T_{2}(12.60 \mathrm{~cm})$ with statistically identical to $T_{5}$ $(10.64 \mathrm{~cm})$; the shortest stalk being in treatment $T_{1}(8.52$ $\mathrm{cm})$. 
Table 3. Effects of spent mushroom compost on length of stalk, diameter of stalk, diameter of pileus and thickness of pileus of milky white mushroom

\begin{tabular}{lcccc}
\hline Treatments & $\begin{array}{c}\text { Length of } \\
\text { stalk }(\mathbf{c m})\end{array}$ & $\begin{array}{c}\text { Diameter of } \\
\text { stalk }(\mathbf{c m})\end{array}$ & $\begin{array}{c}\text { Diameter of } \\
\text { pileus }(\mathbf{c m})\end{array}$ & $\begin{array}{c}\text { Thickness of } \\
\text { pileus }(\mathbf{c m})\end{array}$ \\
\hline Control [Soil + Sand $(3: 1)]$ & $8.52 \mathrm{bc}$ & $1.36 \mathrm{c}$ & $6.47 \mathrm{c}$ & $1.43 \mathrm{c}$ \\
$\mathrm{T}_{2}:$ SMC & $12.60 \mathrm{a}$ & $2.62 \mathrm{a}$ & $10.43 \mathrm{a}$ & $2.68 \mathrm{a}$ \\
$\mathrm{T}_{3}$ : SMC + Sand $(3: 1)$ & $7.82 \mathrm{bc}$ & $1.83 \mathrm{bc}$ & $5.36 \mathrm{~d}$ & $1.70 \mathrm{bc}$ \\
$\mathrm{T}_{4}$ : Soil + SMC + FYM $(1: 1: 1)$ & $7.07 \mathrm{c}$ & $1.88 \mathrm{bc}$ & $6.14 \mathrm{~cd}$ & $1.88 \mathrm{~b}$ \\
$\mathrm{~T}_{5}$ : SMC + FYM (1:1) & $10.64 \mathrm{ab}$ & $2.20 \mathrm{ab}$ & $8.92 \mathrm{~b}$ & $2.44 \mathrm{a}$ \\
\hline Level of significance & $*$ & $*$ & $* *$ & $* *$ \\
SE $( \pm)$ & 0.93 & 0.18 & 0.33 & 0.13 \\
\hline
\end{tabular}

The same letters within a column are not significantly different by Duncan's Multiple Range Tests at the $5 \%$ level. *= Significant at $5 \%$ level, $* *=$ Significant at $1 \%$ level.

Stalk diameter was also affected significantly by different treatments. Treatment $\mathrm{T}_{2}(2.62 \mathrm{~cm})$ also showed the highest mean diameter of stalk with statistically identical to $\mathrm{T}_{5}(2.20 \mathrm{~cm})$. Treatment $\mathrm{T}_{1}(1.36$ $\mathrm{cm})$ displayed the lowest stalk diameter. Diameter of pileus was found to vary from 5.36 to $10.43 \mathrm{~cm}$, with the highest being in treatment $\mathrm{T}_{2}$ and the lowest being in treatment $T_{3}$. Significant differences were also recorded on different treatments for thickness of pileus, which ranged from 1.43 to $2.68 \mathrm{~cm}$, with the highest being in treatment $T_{2}$ and the lowest being in treatment $T_{1}$.

Relationship of economic yield with $\mathrm{pH}, \mathrm{EC}$, particle density and organic carbon of casing materials: In the present study, biological and economical yields were found higher and statistically similar to SMC: Soil: FYM (1:1:1); SMC: Sand (3:1) and SMC where pH, EC, particle density and organic carbon range were 7.167.82, 1.69-1.84 mmhos $\mathrm{cm}^{-1}, 1.52-1.90 \mathrm{~g} \mathrm{cc}^{-1}$ and 11.3$15.8 \%$ respectively (Fig. 2). Mushroom yields were found lower in Soil : Sand (3:1) with statistically similar result of SMC: FYM (1:1). pH, EC and OC were found very low $\left(5.02,0.16\right.$ mmhos $\mathrm{cm}^{-1}$ and $0.97 \%$, respectively) in Soil: Sand (3:1) treatment and very high (8.18, 2.97 mmhos $\mathrm{cm}^{-1}$ and $16.3 \%$, respectively) in SMC : FYM (1:1) whereas the particle density being $2.57 \mathrm{~g} \mathrm{cc}^{-1}$ and $1.29 \mathrm{~g} \mathrm{cc}^{-1}$ respectively.
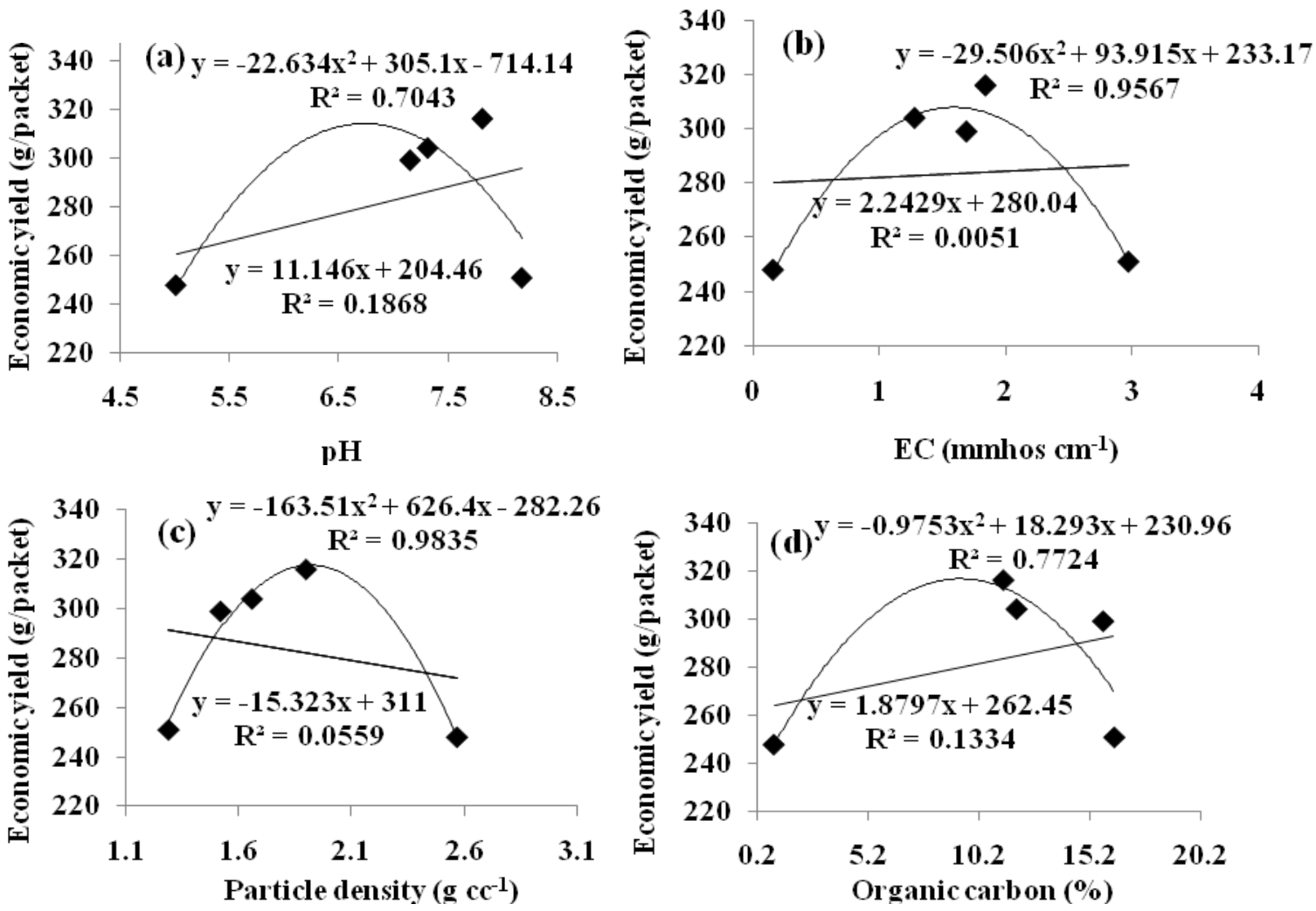

Fig 2. Relationship between (a) pH, (b) EC, (c) particle density, (d) organic carbon (\%) of casing material and economic yield of milky white mushroom 


\section{Discussion}

This study was conducted to assess the suitability of SMS through composting in mushroom production to manage mushroom waste in a productive way. Inner temperature degrees of the spent mushroom compost were monitored and compost maturity was tested to ensure matured and stable compost. After that spent mushroom compost was used as supportive casing material in which the sporophores developed. Mushroom growers in different countries have been using different types of casing materials depending upon their availability. In Bangladesh, mushroom farmers generally use mixture of loamy soil and sand (3:1) as a casing. In the present study comparison was made between the uses of SMC, its combination with other material and farmers' practice (soil: sand, 3:1) to observe the possibility of the reuse of mushroom waste in milky mushroom production. Composting was done as pasteurization or aerobic composting of SMS (Szmidt, 1994) and thus was produced stable or finished spent mushroom compost to use as casing material.

Mixture of spent mushroom substrate with FYM and soil might have improved the physical and chemical properties of the casing media which resulted in better mushroom yield. Biological yield and economic yield were found higher in Soil: SMC: FYM (1:1:1) with statistically similar to SMC: Sand (3:1) and SMC where $\mathrm{pH}, \mathrm{EC}, \mathrm{OC}$ and particle density range were 7.16-7.82, $1.69-1.84$ mmhos $\mathrm{cm}^{-1}, 11.3-15.8 \%$ and $1.52-1.90 \mathrm{~g}$ $\mathrm{cc}^{-1}$, respectively. $\mathrm{pH}, \mathrm{EC}, \mathrm{OC}$ and particle density below or above this range reduced the yield of milky white mushroom. Quality of casing material affects the yield of mushroom as it stimulates the fruit body initiation and regulates the moisture, temperature and certain other factors substrate i.e. physical, chemical, microbiological and nutritional (Singh et al., 2007). It is well agreed that physical and chemical properties of casing like water holding capacity, porosity, bulk density, $\mathrm{pH}$ and electrical conductivity play very important role during mushroom production (Jarial et al., 2005). Water holding capacity to supply water, sufficient porosity and suitable chemical and microbiological characteristics are important requirement of materials used as casing for the growth of mycelium and sporophores (Farsi et al., 2011). Various workers have suggested different ranges of casing $\mathrm{pH}$ for good mushroom yield. These include 5.5-8.0 (Jarial et al., 2005), 6.8-7.16 (Singh et al., 2000). Rangel et al. (2006) indicated slightly acid values (5.50 and 5.92) for coconut fibre and slightly basic values of Black soil with $100 \mathrm{~kg}$ calcium carbamate $\mathrm{m}^{-3}$ (7.6 and 8.1). According to Bokaria et al. (2014), $\mathrm{pH}$ of the casing soil should be neutral to alkaline. Slightly basic values (7.6-8.1) are better suited for the growth of the mycelium (Rangel et al., 2006). In the present study mushroom production was found higher in the $\mathrm{pH}$ range of 7.16-7.82.
Higher yield of milky white mushroom was found between the EC ranges of 1.69-1.84 mmhos $\mathrm{cm}^{-1}$. Soils contained low in soluble salts and electrical conductivity was found better for the production of mushroom (Bokaria et al., 2014). The high value of EC was found harmful for fructification of button mushroom (Choudhary et al., 2009). Gimenez and Gonzalez (2008) observed the EC values of around $1600 \mathrm{mS} \mathrm{cm}^{-1}$ to be a threshold above which a substantial yield reduction could be expected. Casing layer containing 11.3-15.8\% OC produced the higher biological and economic yield than others casing treatment. In case of particle density, higher yield was obtained between the ranges of 1.52$1.90 \mathrm{~g} \mathrm{cc}^{-1}$. The increase in particle density leads to a decrease in total pore space. Porosity is a very important factor in determining the economic potential of a casing material since both mycelium and nutrients should have an easy access to the upper part of casing layer in order to promote good development of the fruiting bodies (Sassine, 2005).

In the study, after casing, primordia were initiated early in control [Soil + Sand (3:1)] treatment with statistically similar time of SMC: Sand (3:1) and SMC. But no significance difference was observed in case of primordia initiation to the $1^{\text {st }}$ harvest. For the $3^{\text {rd }}$ harvest, less time was required for SMC treated casing layer compared to Soil: Sand (3:1). Among the SMC treatments, the lowest time required to primordia initiation was found in SMC: Sand (3:1) followed by SMC and for the $3^{\text {rd }}$ harvest SMC + FYM (1:1) followed by the time of SMC: Sand (3:1) and SMC. It can be inferred that for achieving 3 harvests, SMC + FYM (1:1) treatment produced milky white mushroom earlier than other treatments.

Biological and economic yields were the highest in Soil + SMC + FYM (1:1:1) with statistically similar yield of SMC + Sand (3:1) and SMC followed by SMC + FYM (1:1) and Soil + Sand (3:1). Length and diameter of stalk, diameter and thickness of pileus was found higher in SMC casing treatment and number of effective fruiting bodies was observed the highest in SMC + Sand (3:1) followed by Soil + SMC + FYM (1:1:1). SMC + Sand (3:1) produced the highest number of effective fruiting bodies but length \& diameter of stalk and diameter \& thickness of pileus were not found the highest in SMC. On the other hand, only SMC $\left(T_{2}\right)$ application produced milky white mushroom with the highest length and diameter of stalk and also diameter and thickness of pileus, but the number of effective fruiting bodies production was found lower than the other treatments. Among all treatments, Soil + SMC + FYM (1:1:1) produced the highest biological and economical yields with statistically similar result to SMC + Sand (3:1) and SMC. This result is supported by the results of Singh et al. (Singh et al., 2007) who found better yield of mushroom by using the mixture of spent compost + FYM + Sand + Garden soil (1:1:1:1 v/v). Jarial et al. (2005) also obtained the highest mushroom 
Reuse of spent mushroom substrate as casing material

yield with the combination of spent compost +8 per cent calcium carbonate. Amin et al. (2010) reported the maximum biological efficiency in cowdung \& soil, farm-yard manure, spent mushroom substrate casing layer compared to soil \& sand casing materials. The greatest stalk length and diameter were also observed with the spent mushroom substrate casing material.

\section{Conclusion}

Reuse of mushroom waste is a great solution in terms of mushroom waste management. Reuse of spent mushroom substrate as casing material increase milky white mushroom production with decrease the waste disposal problem in environmentally sound way. From the study it can be concluded that SMS compost supported the growth of sporophores and fulfilled the requirement of the production process of milky white mushroom as the number of effective fruiting bodies, biological yield and economic yield were significantly influenced by SMC treated mushroom. Compared to farmers' practice (control), casing treatments SMC, the SMC + Sand (3:1) and Soil + SMC + FYM (1:1:1) produced higher yields whose $\mathrm{pH}, \mathrm{EC}, \mathrm{OC}$ and particle density range were $7.16-7.82,1.69-1.84$ mmhos $\mathrm{cm}^{-1}$, $11.3-15.8 \%$ and $1.52-1.90 \mathrm{~g} \mathrm{cc}^{-1}$, respectively. Casing layers contained below or above these range of $\mathrm{pH}, \mathrm{EC}$, $\mathrm{OC}$ and particle density reduced the yield of milky white mushroom. Among these three treatments, SMC and SMC + Sand (3:1) produced less but statistically similar yield to Soil + SMC + FYM $(1: 1: 1)$ but in case of the time from casing to primordia initiation and for the $3^{\text {rd }}$ harvest took shorter time than Soil + SMC + FYM (1:1:1). So, considering yield along with time required to harvest, SMC or SMC + Sand (3:1) can be recommended to use as casing layer. On the otherhand SMC or SMC + Sand (3:1) will also reduce the cost of casing layer as FYM will not be needed.

\section{Acknowledgment}

The authors are grateful to the Ministry of Science and Information \& Communication Technology, the Peoples' Republic of Bangladesh for supporting by a research grant through a scholarship to the author R. Ashrafi for higher studies leading to the $\mathrm{PhD}$ degree. Authors are also thankful to the Department of Soil Science, Bangladesh Agricultural University, Mymensingh for providing necessary facilities.

\section{References}

Amin, S.M.R. 2008. Mushroom in Bangladesh: Past, present and future. Abstract of the Annual Botanical Conference 2007, March 7-9, JU, Savar, Dhaka. Abstract no.-122. pp 61.

Amin, R., Khair, A., Alam, N. and Lee, T.S. 2010. Effect of different substrates and casing materials on the growth and yield of Calocybe indica. Mycobiology, 38(2): 97-101.

BCAS (Bangladesh Centre for Advanced Studies). 2012. A proposal on waste management and recycling program in non-forma schools of Bangladesh, submitted to the British Council, British High Commission, Dhaka, by Bangladesh Centre for Advanced Studies, Dhaka, 2001. www.bcas.net.
Bokaria, K., Balsundram, S. K., Bhattarai, I. and Kaphle, K. 2014. Commercial production of milky mushroom (Calocybeindica). MRJASSS, 2(2): 32-37.

Chakraborty, U. and Sikdar, S.R. 2010. Intergenic protoplast fusion between Calocybeindica (milky mushroom) and Pleurotus Florida aids in the qualitative and quantitative improvement of sporophore of milky mushroom. World J Microbiol Biotechnol, 26(2): 213-225.

Choudhary, D.K. 2011. First preliminary report on isolation and characterization of novel Acinetobacter spp. in casing soil used for cultivation of button mushroom, Agaricus bisporus (Lange) Imbach. Available at http://www.ncbi.nlm.nih.gov /pmc/articles/PMC3191781/ accessed on 15.2.2009

Choudhary, D., Agarwa, 1.P.K. and Johri N. 2009. Characterization of functional activity in composted casing amendments used in cultivation of Agaricus bisporus (Lange) Imbach. Indian $J$ of Biotechnol, 8: 97-109.

Danny, L.R. 1992. Commercial mushroom production. Horticultural Research Institute of Ontario Vineland Station. Ontario Ministry of Agriculture and Food Publication,350(5): 37-38.

Farsi M., Malekzadeh K. and Jalalzadeh, B. 2011. Recycling of mushroom peat casing soil through plastic mesh. Proceedings of the $7^{\text {th }}$ International Conference on Mushroom Biology and Mushroom Products (ICMBMP7).

Gimenez, A.P. and Gonzalez, J.E.P. 2008. Evaluation of casing materials made from spent mushroom substrate and coconut fibre pith for use in production of Agaricusbisporus (Lange) imbach. Span J Agric Res, 6(4): 683-690.

Gomez, K.A. and Gomez, A.A. 1984. Statistical Procedures for Agricultural Research.John Wiley \& Son's.Inc. New York. P. 141-177.

Gulser, C. and Peksen, A. 2003. Using tea waste as a new casing material in mushroom (Agaricusbisporus (L. Sing.) cultivation. Bioresour Technol, 88(2): 153-156.

Gupta, Y. and Dhar, B.L. 1993. Spawned casing: Effect on yield of Agaricus bisporus. Indian J Mycol Pl Pathol, 19(2): 225-227.

Hayes, W.A., Shandilya, T.R. 1977. Casing soil and compost substrates used in the artificial culture of Agaricus bisporus. Appl Environ Microbiol, 60: 1538-1546.

Jackson, M.L. 1973. Soil Chemical Analysis. Prentice Hall of India, Private Limited, New Delhi, India.

Jarial, R.S., Shandilya, T.R. and Jarial, K. 2005. Casing in mushroom beds-a review. Agril Rev, 26(4): 261-271.

Krishnamoorthy, A.S., Muthuswamy, M.T. and Nakkeeran, S. 2000. Technique for commercial production of milky mushroom Calocybeindica P\&C. Indian J Mushroom, 18: 19-23.

Levanon, D., Harder, Y. and Wuest, P.J. 1994. Nature and use of spent mushroom substrate. Compost Sci Util, 2(2): 22-23.

Pani, B.K. 2012. Sporophore production of milky mushroom (Calocybeindica) as influenced by depth and time of casing. Intl J Adv Biol Res, 2(1): 168-170.

Purkayastha, R.P., Chandra A. 1985. Manual of Indian edible mushrooms. Today and Tomorrows Printers and Publishers, New Delhi. P. 192-194.

Rangel, J.I., Leal, H., Palacios-Mayorga, S., Sanchez, S., Ramirez, R. and Mendez-Garcia, T. 2006. Coconut fiber as casing material for mushroom production. TERRA Latinoamericana, 24(2): 207-213.

Sample, K.T., Reid, B.J., Fermor, T.R. 2001. Impact of composting strategies of the treatment of soils contaminated with organic pollutants. A Review Environ Pollut, 112: 269-283.

Sassine Y.N., Ghora, Y., Kharrar, M., Bohme, M. and AbdelMawgoud, A.M.R. 2005. Waste paper as an alternative for casing soil in mushroom (Agaricus bisporus) production. $J$ Appl Sci Res, 1: 277-284.

Sassine, Y.N., Karam, K., Mounayar, D. and Abdel-Menhem, G. 2010. Prospective of local oyster mushroom production in Lebanon. $J$. Appl. Sci. Res., 6(12): 2139-2142. 
Sharma, S.S., Doshi, A., Trivedi A. and Kothari K.L. 1997. Evaluation of the suitability of different casing materials for Calocybe indica $P$ and C. Mushroom Res, 6(2): 81.

Singh, M., Singh, A.K. and Gautam, R.K. 2007. Effect of casing and supplementation on yield of milky mushroom (Calocybe indica). Indian Phytopath, 60(2): 191-193.

Singh, M., Singh, R.P. and Chaube, H.S. 2000. Impact of physicochemical properties of casing on yield of Agaricusbisporus (Lange) Imbach,in Science and Cultivation of Edible Fungi, L.J.L.D. van Griensven, Ed., Balkema, Rotterdam, The Netherlands. P. 441-446.

Suess, A. and Curtis, J. 2009. Report: Value added strategies for spent mushroom substrate in BC. Prepared for British Columbia Mushroom Industry, 2006, http://www.agf.gov.bc.ca /mushroom/guide/value_added_strategies.pdf .

Szmidt, R.A.K. 1994. Recycling of spent mushroom substrate by aerobic composting to produce novel horticultural substrates. Compost Sci Util, 2(3): 63-72.
Szmidt, R.A.K. and Convay, P.A. 1995. Leaching of recomposted spent mushroom substrates (SMS). Sci and Cult of Edi Fungi, 2: 901-905.

Tajbakhsh, J., Abdoli, M.A., Goltapeh, E.M., Alahdadi, I., Malakouti, M.J. 2008. Trend of physic-chemical properties changes in recycling spent mushroom compost through vermicomposting by epigeic earthworms Eisenia foetida and E. andrei. J Agril Tech, 4:185-198.

Tewari, R.P. 2005. From Director's desk. Mush. Newsl., National Research Center for Mushroom, Chambagat, Solan. P. 8.

Visvanathan, C. and Glawe, U. 2010. Domestic solid waste management in South Asian countries-Acomparative analysis. Presented at 3 R South Asia Expert Workshop, 2006. http://www.faculty.ait.ac.th/visu/Prof\%20Visu's\%20CV/Confer ance/25/3R-MSWM.\%20Visu.pdf. 